\title{
D-STATCOM Optimal Allocation Based On Investment Decision Theory
}

\author{
Yongjun Zhang ${ }^{1, ~ a, ~ Y i f u ~} \mathrm{Mo}^{1, b}$ and Huazhen $\mathrm{Cao}^{2, \mathrm{c}}$ \\ ${ }^{1}$ School of Electric Power, South China University of Technology, Guangzhou 510640, China; \\ ${ }^{2}$ Grid Planning \& Research Center, Guangdong Power Grid Corporation, Guangzhou 510086, \\ China. \\ azhangjun@scut.edu.cn, b578299002@qq.com, ccaohuazhen@gd.csg.cn
}

\begin{abstract}
In order to avoid certain types of voltage sags, this paper proposed an optimal method to allocate D-STATCOM capacity, which is based on Investment Decision Theory and a $10 \mathrm{kV}$ distribution line equivalent model. In addition, the Investment Decision Theory was presented in this paper, in order to establish a D-STATCOM optimal allocation model with the investment payback period as main index. Some optimization suggestions were raised at the end of this paper, considering the historical data of voltage sags and low voltage release allocation. Finally, the effectiveness of the method is demonstrated by the simulation on a $10 \mathrm{kV}$ distribution feeder in Shenzhen, Guangdong Province, China.
\end{abstract}

Keywords: D-STATCOM; Investment Decision Theory; Voltage Sags; Optimal Allocation.

\section{Introduction}

A large area of low voltage trip in the city caused by low voltage sags, which leads to sudden loss of the load, is becoming a huge threat to the reliability of power grid operation. There is no doubt that voltage sags have been a top issue affects the power quality [1].

STATCOM has obvious advantages in the cost, complexity of control and function, is more applicable to the larger capacity user, and has thus become the main means and measures to solve the voltage sag and voltage instability [2]. A lot of researches have been made on the simulation and analysis of the practical result in using D-STATCOM to suppress voltage sag.

Subject to the price, it is often necessary to study the method of D-STATCOM optimal configuration in engineering applications $[3,4]$. Researchers abroad use a variety of algorithms to determine the optimal location and capacity of STATCOM in the system [5,6]. Since the above methods do not fully consider the actual setting value of the users' under voltage tripping device and the actual voltage sag in distribution network, the Cost estimation of voltage sags shall have very big difference with the actual conditions and cannot meet the requirements of the project. As the power quality monitor is widely used, it is more feasible to collect the voltage sag data in the distribution network, which allows us to configurate D-STATCOM better.

In order to give the consideration to the voltage sag compensating capability and economy of the distribution network, this paper established a D-STATCOM optimal allocation model with the investment payback period as main index based on Investment Decision Theory, and demonstrated the effectiveness of the method by the simulation on a $10 \mathrm{kV}$ distribution feeder in Shenzhen, Guangdong Province, China.

\section{2. $10 \mathrm{kV}$ distribution line equivalent model}

After choosing a $10 \mathrm{kV}$ feeder and dealing with the rest of the grid equivalently, the $10 \mathrm{kV}$ distribution line equivalent model is established as shown in Fig 1. VSH refers to power supply voltage; $\mathrm{VH}$ is voltage amplitude in distributing side; $\mathrm{XSH}$ refers to the system equivalent reactance; $\mathrm{PL}+\mathrm{jQL}$ and $\mathrm{PH}+\mathrm{jQH}$ is load apparent power and system apparent power, respectively. Besides, all of loads are equipped with circuit breaker with the function of low-voltage tripping. D-STATCOM is connected to $10 \mathrm{kV}$ bus, using the rated voltage control method. 


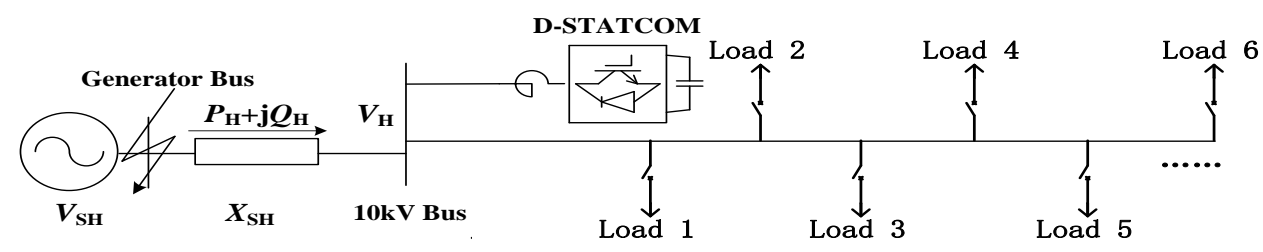

Fig. 1 10kV distribution line equivalent model

All of the load parameters and the setting value of low-voltage tripping are set according to users' information. The voltage sags caused by the external fault are simulated by setting different fault in the generator bus.

In the most extreme case of one kind of the voltage sags, D-STATCOM allocation capacity increases constantly until there are no load losses caused by low voltage leakages so that the allocation capacity will be determined in order to suppress appropriate kind of voltage sags. However, the allocation capacity determined by above mean may be large, which is necessary to come up with an optimal model.

\section{D-STATCOM Optimal Allocation model Based On Investment Decision Theory}

Reference [6] optimized D-STATCOM allocation capacity by minimizing the sum of the economic loss caused by the voltage sags and the cost of D-STATCOM. The total cost is continuously reduced in the optimization used firefly algorithm. By contrast, Investment Decision Theory lays more stress on the transfer rate of funds and the effect of investment. According to this theory, this paper establish a D-STATCOM optimal allocation model with the investment payback period as main index.

The initial investment of D-STATCOM is defined as follows:

$C_{0}=\sum_{i} \delta Q_{\mathrm{C} i}$

Where the unit price of D-STATCOM is $\delta$ RMB $¥ / M v a r$ (including equipment cost and installation cost); $Q_{\mathrm{C} i}$ represents the capacity of D-STATCOM $i$.

The annual maintenance cost of D-STATCOM is defined as follows:

$C_{\mathrm{m}}=\alpha C_{0}=\alpha \sum_{i} \delta Q_{\mathrm{C} i}$

Normally, the annual maintenance cost equals the initial investment multiplied times a coefficient $\alpha$, which is $0 \sim 10 \%$.

The outage loss that can be reduced every year after allocating D-STATCOM is defined as follows:

$$
C_{\mathrm{r}}=\sum_{k} P_{\mathrm{L} k} f_{k} l
$$

Where it represents the voltage sags can be ruduce $f_{k}$ times per year after installing D-STATCOM. $k$ represents different types of voltage sags, and the corresponding amount of load shedding is $P_{\mathrm{L} k}$ MW. The economic loss of load shedding is $l$ RMB¥/MW.

Assume the economic loss of nonconforming products caused by voltage sags can be reduced $\beta$ RMB¥, and the service life of D-STATCOM is T years. The investment is worthy when the reduced loss is bigger than the initial investment and maintance cost of D-STATCOM during its service life.

$$
T\left(C_{\mathrm{r}}+\beta\right) \geq C_{0}+T C_{\mathrm{m}}
$$

Plus into relevant parameters and the following equations can be written, where $P_{\mathrm{t}}$ is the investment payback period.

$$
T \geq \frac{\sum_{i} \delta Q_{\mathrm{C} i}}{\sum_{k} P_{\mathrm{L} k} f_{k} l-\alpha \sum_{i} \delta Q_{\mathrm{C} i}+\beta}=P_{\mathrm{t}}
$$




\section{Survey on voltage sags and low voltage leakage in Shenzhen}

An annual statistics of voltage sags in a $10 \mathrm{kV}$ distribution line of Shenzheng is shown in Fig. 2.

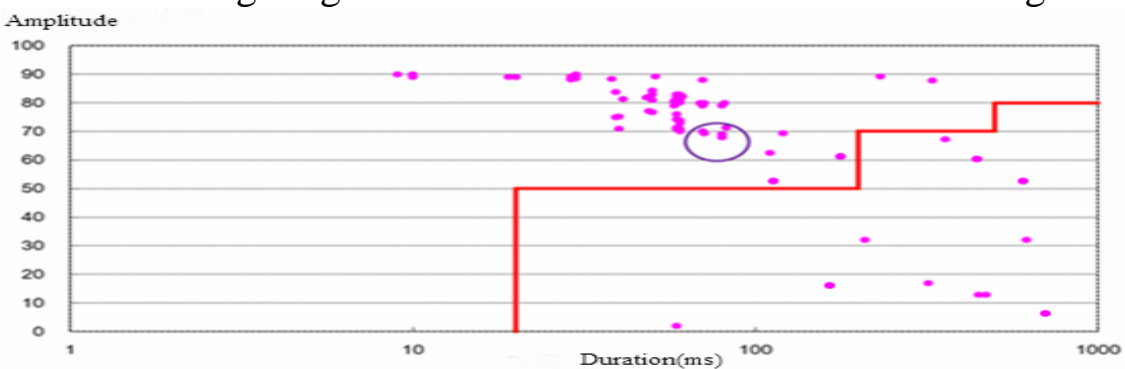

Fig. 2 Annual statistics of voltage sags

The parameters of voltage sags and low voltage leakages are descriped as shown in Table 1 and Table 2.

Table 1 Duration and amplitude of voltage sags

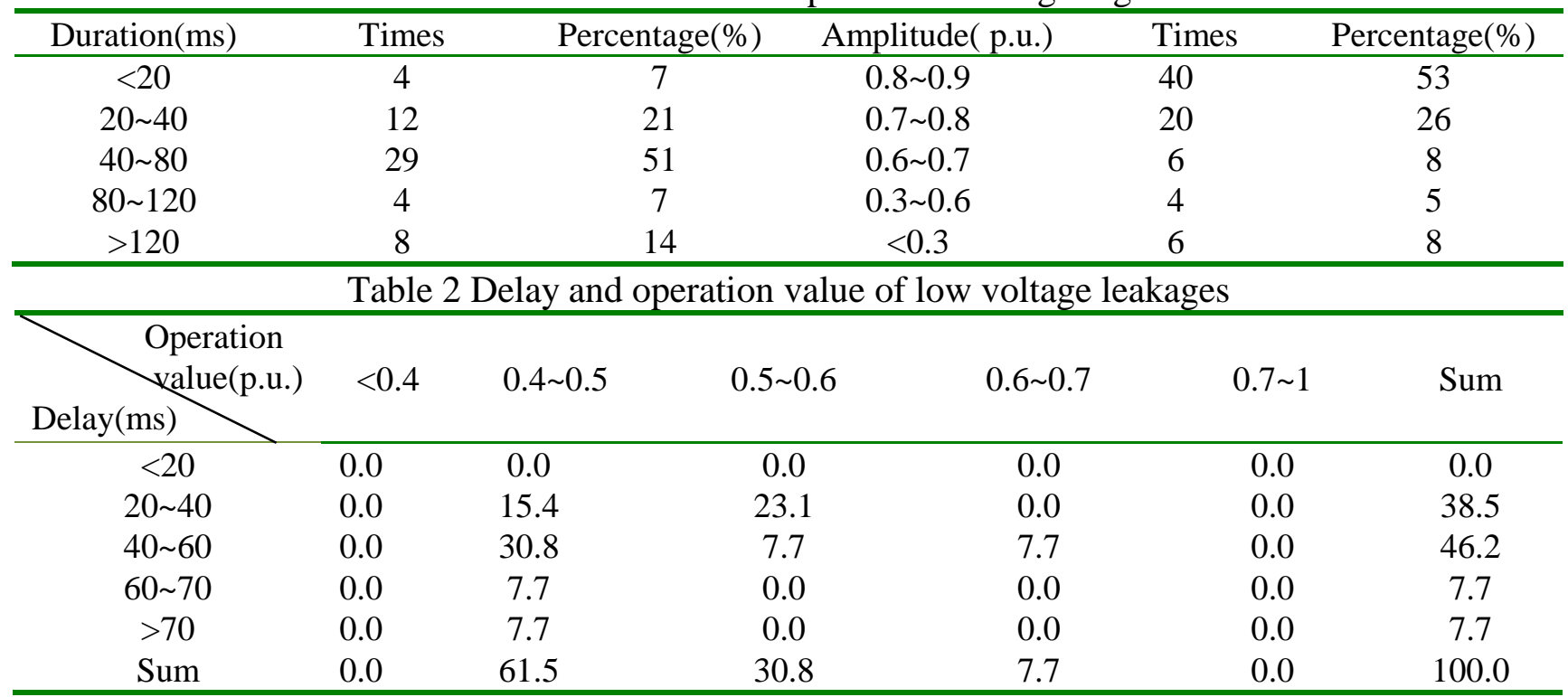

\section{Simulation}

Based on the $10 \mathrm{kV}$ distribution line equivalent model, it is simulated using the BPA software, where Load 1 6 are 0.3MW, 0.8 MW, 0.1 MW, 0.8 MW, 0.2 MW, 0.8MW, respectively. And the load power factors are similarly set up to 0.9 . According to the survey above, the parameters are set as shown in Table 3.

Table 3 Parameters of the loads and low voltage leakages

\begin{tabular}{ccccc}
\hline Load number & Load capacity(MW) & Capacity proportion & $\begin{array}{c}\text { Operation } \\
\text { value(p.u.) }\end{array}$ & Delay(cycle) \\
\hline 1 & 0.3 & $10 \%$ & 0.7 & 3 \\
$2 \sim 3$ & 0.9 & $30 \%$ & 0.6 & 3 \\
$4 \sim 6$ & 1.8 & $60 \%$ & 0.5 & 3 \\
\hline
\end{tabular}

By setting different short-circuit faults in the generator bus, various kinds of voltage sags can be simulated as shown in Table 4.

Table 4 Parameters of the voltage sags

\begin{tabular}{ccccc}
\hline Number & Type of voltage sags & Probability & Amplitude in extreme case(p.u.) & Duration(cycle) \\
\hline Fault 1 & Amplitude $\geq 0.7$ p.u. & $79 \%$ & 0.7 & 5 \\
Fault 2 & Amplitude $\geq 0.6$ p.u. & $87 \%$ & 0.6 & 5 \\
Fault 3 & Amplitude $\geq 0.3$ p.u. & $92 \%$ & 0.3 & 5 \\
\hline
\end{tabular}


In order to determine the allocation capacity needed to suppress appropriate kind of voltage sags, the capacity of D-STATCOM increases slowly from 0 in the process of simulation, until there are no protection actions.

According to the existing survey, $\delta$ is $500,000 \mathrm{RMB} ¥ / \mathrm{Mvar} ; \alpha$ is 0.1 . Besides, it will take this factory $4 \mathrm{~h}$ to restart their production lines after an electricity failure accident, and the loss is $136,000 \mathrm{RMB} ¥ / \mathrm{MW}$ as it is shown in [7], where 1 is $136,000 \mathrm{RMB} ¥ / \mathrm{MW}$. The loss of nonconforming product caused by voltage sags is ignored in the calculation process, where $\beta$ is 0 . Then put them into (5) and the calculation results are shown as shown in Table 5.

Table 5 Results of calculation and simulation

\begin{tabular}{cccc}
\hline Number & $\begin{array}{c}\text { Needed } \\
\text { capacity(Mvar) }\end{array}$ & Load shedding situation & $\begin{array}{c}\text { Investment payback } \\
\text { period(year) }\end{array}$ \\
\hline Fault 1 & 0.7 & $0.3 \mathrm{MW}$ for 3 times & 4.0 \\
Fault 2 & 3.3 & 1.2MW for 2 times, 0.3MW for 7 times & 3.7 \\
Fault 3 & 11.5 & 3MW for 2 times, 1.2MW for 4 times, 0.3MW for 7 & 4.9 \\
\hline
\end{tabular}

Assume the operation value of Load 1 is 0.6 p.u. , calculate and simulate again. We can get the results as shown in Table 6.

Table 6 Results after optimizing the parameters of low voltage leakages

\begin{tabular}{cccc}
\hline Number & $\begin{array}{c}\text { Needed } \\
\text { capacity(Mvar) }\end{array}$ & Load shedding situation & $\begin{array}{c}\text { Investment payback } \\
\text { period(year) }\end{array}$ \\
\hline Fault 1 & 0 & 0 & 0 \\
Fault 2 & 0.3 & 1.2MW for 2 times & 0.5 \\
Fault 3 & 10.5 & 3MW for 2 times, 1.2MW for 4 times & 5.6 \\
\hline
\end{tabular}

\section{Summary}

From the results of the simulation and economic analysis, we cannot expect that D-STATCOM can suppress all kinds of voltage sags, which is unreasonable in technology and economy. According to the parameters of low voltage leakages, it is more reasonable to avoid power failure by optimizing the parameters when users demand low power quality. D-STATCOM of a certain capacity is necessary to suppress most of voltage sags when users demand high power quality.

\section{References}

[1]. Chapman D, "Introduction to power quality," in Power Quality Application Guide-Copper Development Association, May 2007 [Online].Available: http://www.cda.org.uk/pqp/pqag.htm

[2]. Zhang, Y. J., Chen, C., Li, Y., \& Wu, G. B. (2010). Dynamic voltage support planning for receiving end power systems based on evaluation of state separating and transferring risks. Electric Power Systems Research, 80 (12), 1520-1527.

[3]. Xubin Liu, Canbing Li and Kai Sun, "Voltage support for industrial distribution network by using positive/negative sequence passivity-based control", Power Electronics and Motion Control Conference (IPEMC-ECCE Asia) 2016 IEEE 8th International, pp. 674-679, 2016.

[4]. X. Hongxia and Z. Yanyun, "Cooperative Control and Application of D-STATCOM and Switched Capacitor Branch," Intelligent Computation Technology and Automation (ICICTA), 2011 International Conference on, Shenzhen, Guangdong, 2011, pp. 384-387.

[5]. Milanovic J V, Zhang Yan, "Global Minimization of Financial Losses Due to Voltage Sags With FACTS Based Devices," Power Delivery, IEEE Transactions on , vol.25, no.1, pp.298,306, Jan. 2010

[6]. Farhoodnea M, Mohamed A., Shareef H, Zayandehroodi H., "Optimum D-STATCOM placement using firefly algorithm for power quality enhancement," Power Engineering and 
Optimization Conference (PEOCO), 2013 IEEE 7th International , vol., no., pp.98, 102, 3-4 June 2013

[7]. Tollefson G, Billinton R, Wacker G, Chan E, Aweya J, "A Canadian customer survey to assess power system reliability worth," Power Systems, IEEE Transactions on , vol.9, no.1, pp.443, 450, Feb 1994. 